\title{
Influence of Alumina Reaction Tube Impurities on the Oxidation of Chemically-Vapor-Deposited Silicon Carbide
}

\author{
Elizabeth Opila*+ \\ Department of Chemical Engineering, Cleveland State University, Cleveland, Ohio 44115
}

Pure coupons of chemically vapor deposited (CVD) SiC were oxidized for $100 \mathrm{~h}$ in dry flowing oxygen at $1300^{\circ} \mathrm{C}$. The oxidation kinetics were monitored using thermogravimetry (TGA). The experiments were first performed using high-purity alumina reaction tubes. The experiments were then repeated using fused quartz reaction tubes. Differences in oxidation kinetics, scale composition, and scale morphology were observed. These differences were attributed to impurities in the alumina tubes. Investigators interested in high-temperature oxidation of silica formers should be aware that high-purity alumina can have significant effects on experimental results.

\section{Introduction}

TN THIS laboratory, we are attempting to understand the basic 1 mechanisms occurring in the oxidation of silicon-based ceramics, i.e., $\mathrm{SiC}$ and $\mathrm{Si}_{3} \mathrm{~N}_{4}$. We observed that the impurity effects associated with high-purity alumina reaction tubes on the oxidation of $\mathrm{SiC}$ in dry oxygen were very pronounced. These effects are well known in the semiconductor industry for the oxidation of silicon, ${ }^{1}$ where high-purity fused quartz tubes are generally used for the oxidation process at temperatures of $1200^{\circ} \mathrm{C}$ or less. Nevertheless, most studies for the oxidation of $\mathrm{SiC}$, where conclusions have been made about intrinsic oxidation mechanisms, have been conducted in high-purity alumina or mullite tubes owing to the higher oxidation temperatures of interest for $\mathrm{SiC}\left(1200-1500^{\circ} \mathrm{C}\right)$.

Precedents for the observed impurity effects of high-purity alumina tubes can also be found outside the semiconductor literature. Wagstaff and Richards ${ }^{2}$ noted that contamination in even the highest-purity alumina tubes increased the crystallization rates of silica. The alumina tubes were heated under vacuum at operating temperatures for long times to minimize this problem. Choi, Fischbach, and $\mathrm{Scott}^{3}$ found that parabolic rate constants for the oxidation of silicon in $99.8 \%$ pure alumina tubes were about a factor of 7 higher than other values reported in the literature. After changing to silica tubes, they found good agreement with the literature. In recent studies in this laboratory, it was noted that alumina tubes had a large effect on the oxidation behavior of $\mathrm{SiC}$ and/or $\mathrm{Si}_{3} \mathrm{~N}_{4}$ in dry oxygen ${ }^{4}$ as well as in $10 \%$ water vapor and oxygen. ${ }^{5}$ However, none of these effects have been well documented. In this note, the effects of impurities associated with high-purity alumina tubes are shown in detail in hopes that future studies of oxidation mechanisms of silica formers be conducted in quartz tubes when intrinsic oxidation behavior is desired.

J. Fergus-contributing editor

Manuscript No. 193027. Received December 7, 1994; approved February 3, 1995.

Member, American Ceramic Society.

Resident Research Associate at NASA-Lewis Research Center, Cleveland, Ohio 44135 .

\section{Experimental Procedure}

CVD SiC coupons $(99.999 \%$ purity, Morton International, Inc., Woburn, MA) of dimensions $3 \mathrm{~cm} \times 1.5 \mathrm{~cm} \times 0.3 \mathrm{~cm}$ were cleaned in detergent, deionized water, acetone, and alcohol. The alumina tubes $(99.8 \%$ purity, Vesuvius/McDanel, Beaver Falls, PA) and fused quartz tubes $(99.995 \%$ purity, Quartz Scientific, Fairport Harbor, $\mathrm{OH}$ ) were cleaned in the same manner as the coupons. The samples were suspended from a microbalance (Cahn 1000, Cahn Instruments, Cerritos, CA) with sapphire rods $(<100$ ppm impurities, Saphikon, Milford, NH) in 1 in.-diameter reaction tubes. Typical impurity levels for sample and TGA tube materials are shown in Table I. Oxygen gas flowed through the vertical reaction tube at a rate of $100 \mathrm{sccm}$ after first being dried with Drierite $\left(\mathrm{CaSO}_{4}\right)$ and $\mathrm{Mg}\left(\mathrm{ClO}_{4}\right)_{2}$. Oxidation was initiated by raising the furnace, already at $1300^{\circ} \mathrm{C}$, up around the sample. Oxidation times were typically $100 \mathrm{~h}$. Sample weight change and temperature were recorded digitally as a function of time. After oxidation, the samples were examined by optical microscopy, X-ray diffraction (XRD), scanning electron microscopy (SEM), energy dispersive spectroscopy (EDS), and secondary ion mass spectrometry (SIMS).

\section{Results and Discussion}

Macrographs of the CVD SiC coupons after 100-h oxidation in alumina and fused quartz tubes in dry flowing oxygen at $1300^{\circ} \mathrm{C}$ are shown in Fig. 1. The two coupons are quite different in appearance. The sample oxidized in an alumina reaction tube is light gray in color and has occasional spots on the scale. The

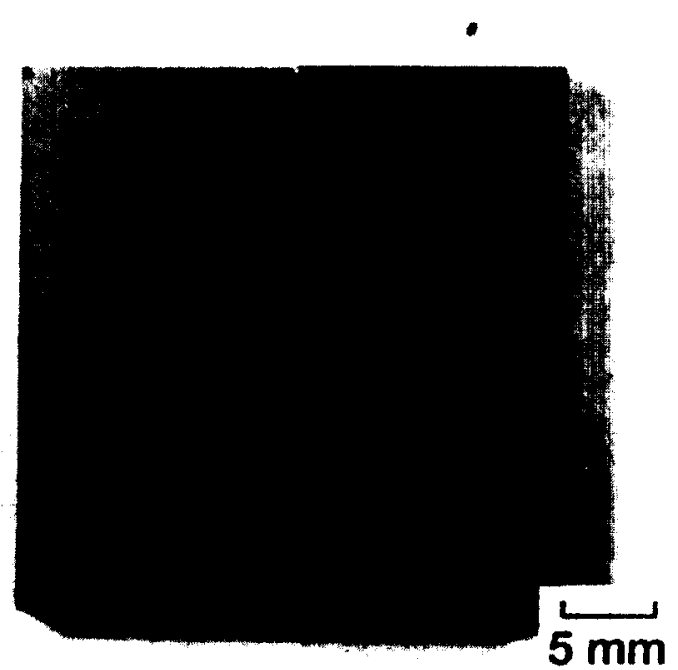

Fig. 1. Macrographs of CVD SiC coupons oxidized for $100 \mathrm{~h}$ at $1300^{\circ} \mathrm{C}$ in dry flowing oxygen. The sample on the left was oxidized in an alumina reaction tube and the sample on the right was oxidized in a fused quartz tube. 
Table I. Manufacturers" Purity Specifications for the (VI) Sample Material and the Reaction Tube Materials

\begin{tabular}{|c|c|c|}
\hline Makrial (mbanuficturer) & $\begin{array}{c}\text { Purily } \\
\text { (\%) }\end{array}$ & $\begin{array}{l}\text { Mandiactures' typical saluce } \\
\text { (ppm by weight) }\end{array}$ \\
\hline CVDSiC (Mortom International) & 90.990 & $\mathrm{Mn}(1.2) \mathrm{Fe}(7.3) \mathrm{Co}(1.0) \mathrm{Ni}(0.6), \mathrm{Cu}(5.5), \mathrm{Zn}(1.5)$ \\
\hline High-purity alumina (McDancl/Vesuvius) & 99.8 & $\begin{array}{l}\mathrm{SiO},(60), \mathrm{MgO}(350), \mathrm{Nat}_{2} \mathrm{O}(80), \mathrm{CaO}(400), \mathrm{Fe}_{2} \mathrm{O},(250), \\
(\mathrm{Cr}, \mathrm{O}, 1<30), \mathrm{TiO},(40), \mathrm{B}, \mathrm{O},(<10), \mathrm{K}, \mathrm{O}(<10)\end{array}$ \\
\hline Fused quartz (Quarts. Scientific) & 99.995 & 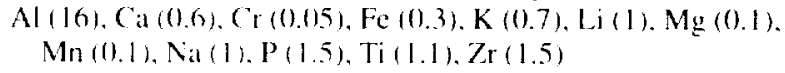 \\
\hline
\end{tabular}

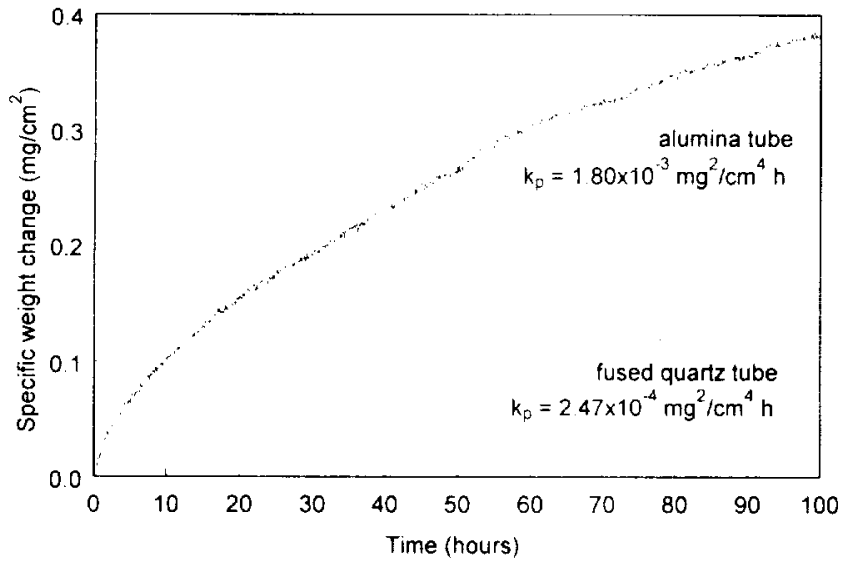

Fig. 2. Oxidation kinetics for CVD SiC coupons axidized al $1.3000 \mathrm{C}$ in dry llowing oxyger.

sample oxidised in the fused quart $/$ tube is much darker in color and hats a very uniform surface.

The oxidation kinetics for the two simples mentioned above are shown in Fig. 2. The rate constant for the sample oxidized in the alumina tube is about an order of magnitude higher than that for the sample oxidized in the fused quartz tube. The kinetic results for oxidation in either tube were very repeatable. The parabolic rate constants measured for three samples oxidized in alumina tubes averaged $(1.81 \pm 0.31) \times 10^{\prime} \mathrm{mg}^{2} /$ $\left(\mathrm{cm}^{4} \cdot \mathrm{h}\right)$. The rate constants mealsured for three samples oxidized in fused quartz tubes averaged $(2.44+0.09) \times 10^{+}$ $\mathrm{mg}^{2} /\left(\mathrm{cm}^{4} \cdot \mathrm{h}\right)$.

The SEM cross sections of the oxide scale for the same two sampless shown in Fig. 1 are shown in Fig. 3. The scale thickness is $4.7 \pm 0.8 \mu \mathrm{m}$ for the sample oxidized in alumina and

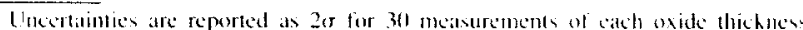
meisured all I-min intervals.
1.6 $\pm 0.4 \mu \mathrm{m}$ for the sample oxidized in fused quart\%. The rate constants can be calculated from the oxide thicknesses assuming a density of $2.32 \mathrm{~g} / \mathrm{cm}^{2}$ for cristobalite as already described." They are $(1.32 \pm 0.04) \times 10{ }^{3}$ and $(1.6 .3 \pm 0.01) \times$ $10{ }^{4} \mathrm{mg}^{2} /\left(\mathrm{cm}^{1} \cdot h\right)$ for the samples oxidized in alumina and fused quartz. respectively. The disparity between these values and those measured directly by TGA is explained as follows. SEM/ EDS observations of oxidized SiC cross sections' have shown that crystalline silica scales crack near the silica/SiC interface leaving a very thin silica layer on the $\mathrm{SiC}$ which is indistinguishable from the underlying $\mathrm{SiC}$. Oxide thickness measurements made from the crack to the outer surface result in a slight underestimation of the oxide thickness, and thus $k$.

The XRI) results shown in Fig. 4 indicate that both tridymite and cristohalite are present in the scale of the sample oxidized in the alumina tube, whereas tridymite is barely detecled in the sample oxidized in the quarty tube. It is known that the formattion of tridymite is enhanced in the presence of impurities.

In previous work. sodium and aluminum impurities were detected by EDS on SiC samples oxidized in $10 \%$ water vapor with alumina tubes. Impurity concentrations in the scale on the sample oxidired in the alumina tube with dry oxygen, however, were below the detectibility limit of EDS. Oxidized coupons were therefore analyded using SIMS (Perkin-Elmer PHI-6.300) SIMS, work performed by AT\&T Analytical Services. Allentown, PA). These results are shown in Fig. 5. The scale grown in the alumina tube has at least an order of magnitude higher sodium content than that grown in the quartz tube. Concentrations were nor calculated because of the tendency of Na ions to be moved within the $\mathrm{SiO}$, layer by the electron current used for charge neutralization. For the same reason the shape of the $\mathrm{Na}$ profile should be considered indeterminate. The $\mathrm{Al}$ concentration profiles, if shown relative to ${ }^{3} \mathrm{Si}$ and for the same sputter time (depth) range, are nearly the same in both scales. The different ranges on the abscissa in Figs. 5(A) and (B) prevent this from being easily seen. Ca concentrations (not shown) were lower than $\mathrm{Na}$ and $\mathrm{Al}$ concentrations and were about the same at the surface of both samples. The Ca concentration in the bulk was about an order of magnitude greater in the scale grown in
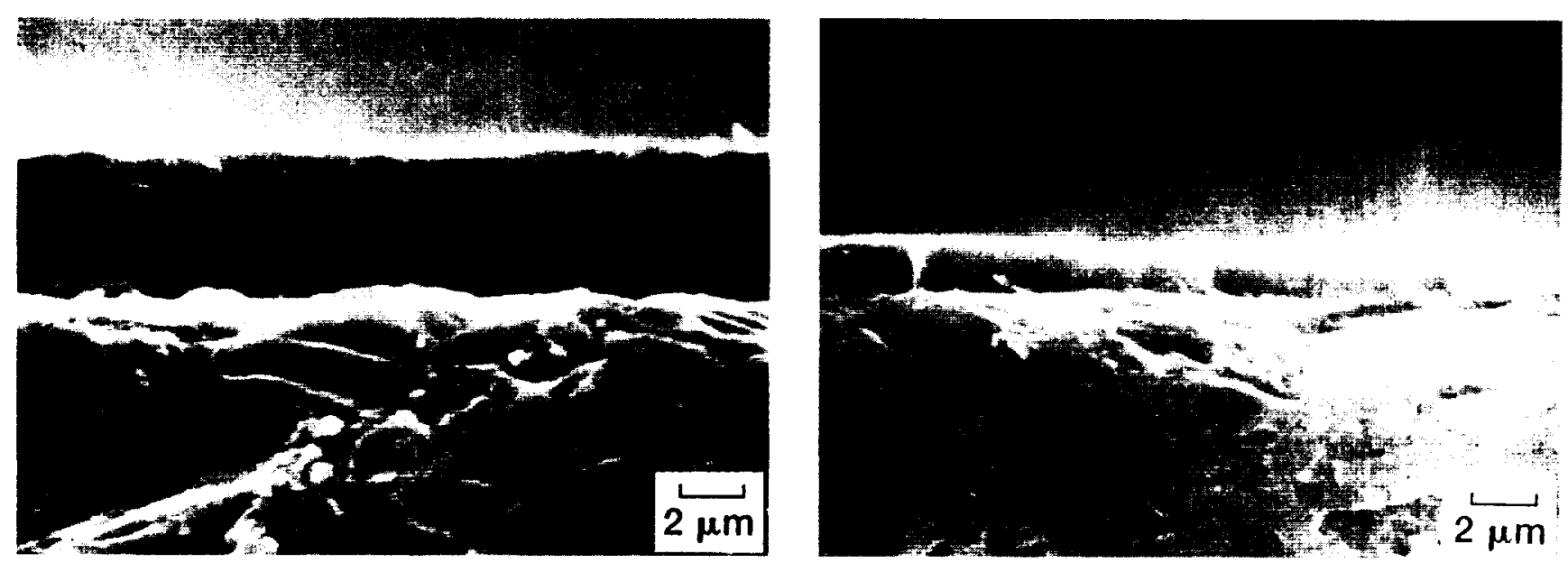

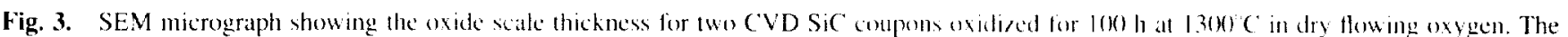
sample on the left was oxidized in an alumina reatction wube and the sample on the right was oxidized in a lused quart/ reaction tube. 

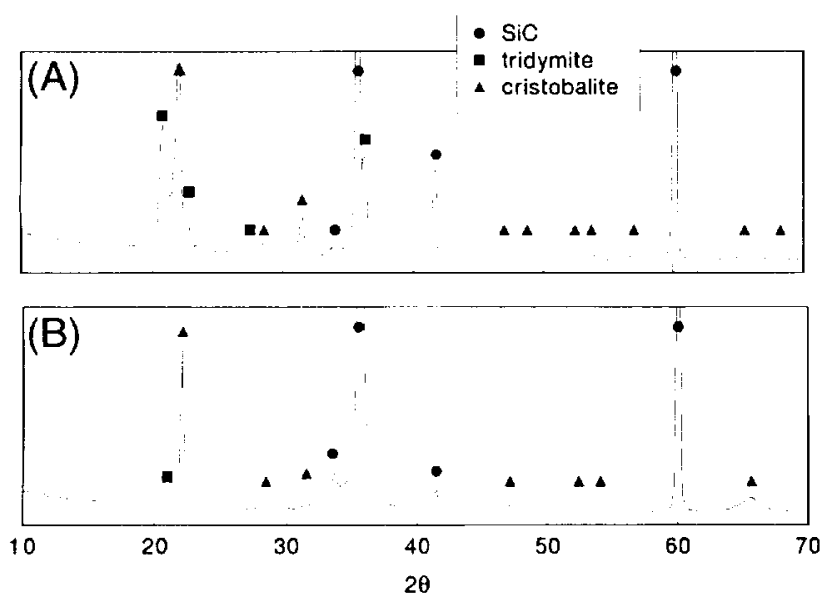

Fig. 4. X-ray diffraction results for two CVD SiC coupons oxidized for $100 \mathrm{~h}$ at $13000^{\circ} \mathrm{C}$ in dry flowing oxygen. Diffraction pattern $\mathrm{A}$ was obtained from the coupon oxidized in an alumina reaction tube and pattern B was obtained from the coupon oxidized in a fused quartz tube

the alumina tube. Levels of $\mathrm{Mg}, \mathrm{K}$, and $\mathrm{Li}$ were about the same in both coupons. Fe impurity concentrations were not measured because ${ }^{56}$ Fe could not be differentiated from ${ }^{56} \mathrm{Si}$.

It has been demonstrated that sodium accelerates the oxidation of $\mathrm{SiC}$ due to the increased permeation of molecular oxygen through the oxide, which may be attributed to the formation

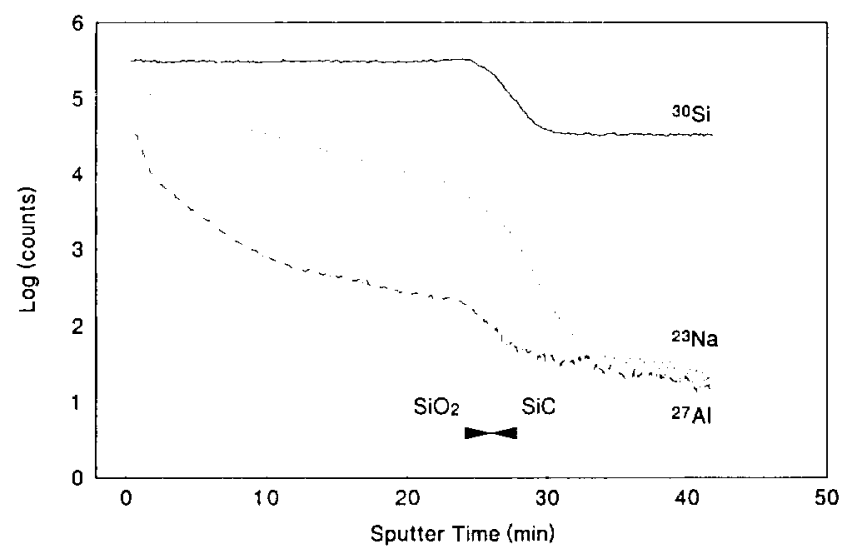

(A)

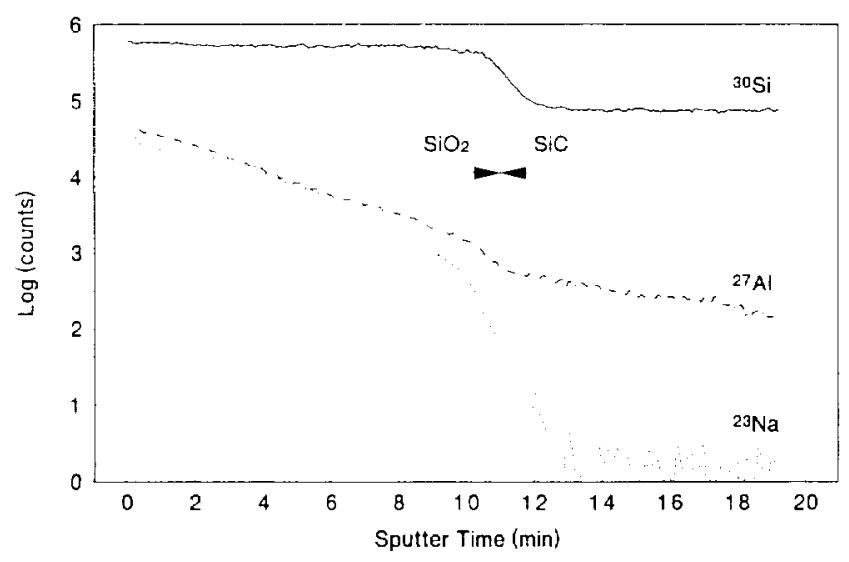

(B)

Fig. 5. SIMS profiles for $\mathrm{Nat}$ and $\mathrm{Al}$ impurities in the $\mathrm{SiO}$, scale on $\mathrm{SiC}$ which had been oxidized in aln alumina reaction tube (A) and a fused guart/ reaction tube (B). Note that the range for the abscissa is different in $(A)$ and $(B)$. of nonbridging oxygens." It is therefore believed that sodium impurities from the alumina tube found in the silica scale are responsible for the enhanced oxidation rates compared to those measured in quartz tubes.

From $\mathrm{SiC}$ oxidation experiments at lower temperatures $\left(1200^{\circ} \mathrm{C}\right)$ where crystallization of silica is less favored, it has been observed that samples oxidized in fused quartz tubes have amorphous scales whereas samples oxidized in alumina tubes are partially crystalline. " This is in agreement with the observations of Wagstaff and Richards ${ }^{2}$ that impurities increase the crystallization rate of silica. While the effect of silica crystallization on the oxidation rate of $\mathrm{SiC}$ is complicated " crystallization is generally believed to decrease oxidation rates." Therefore, impurity modification of the scale rather than crystallization of the scale best explains the enhanced oxidation rates observed here in alumina tubes.

Recent work has been conducted by Ogbuji and Opilat on the oxidation of $\mathrm{SiC}$ in fused quartz tubes between $1200^{\circ}$ and $1500^{\circ} \mathrm{C}$. No change in oxygen transport mechanism was observed to occur in this temperature range. It is suggested that the observed increase in oxidation activation energy found in other studies near $1400{ }^{\circ} \mathrm{C}$ (summarized in Ref. 4) might be due to reaction tube impurity effects.

An aging effect for impurities in the alumina tubes has been observed. After an alumina tube has been used at temperature for a long time $(>2000 \mathrm{~h})$, impurity effects on the oxidation kinetics become insignificant relative 10 oxidation in fused quartz tubes. This is demonstrated in Fig. 6. The aging effect may be explained by the volatilization of $\mathrm{Na}$ impurities over time. Variations in experimental results with time in any impurity-sensitive process conducted in alumina tubes may be due to this aging effect. It is suggested that fused quartz tubes be used when possible to avoid these impurity effects. Fused quartz tubes have been used successfully in this laboratory at temperatures as high as $1500^{\circ} \mathrm{C}^{4}$ Use of fused yuartz tubes in the $1200^{\circ}$ to $1500^{\circ} \mathrm{C}$ range results in crystallization of the tube; however, this is not a problem until the tube is cooled below the $\beta$-to- $\alpha$ cristobalite transition temperature (about $270^{\circ} \mathrm{C}$ ) at which time surface cracking occurs.

\section{Conclusions}

It has been demonstrated that the oxidation of pure CVD SiC is very sensitive to $\approx 100 \mathrm{ppm}$ level of impurities. The oxidation kinetics, scale composition, and morphology were all affected by impurities (probably sodium) in "high-purity" alumina reaction tubes. It has been shown that fused yuartz tubes provide a cleaner environment for high-temperature oxidation of silica formers in which growth rates are impurity sensitive.

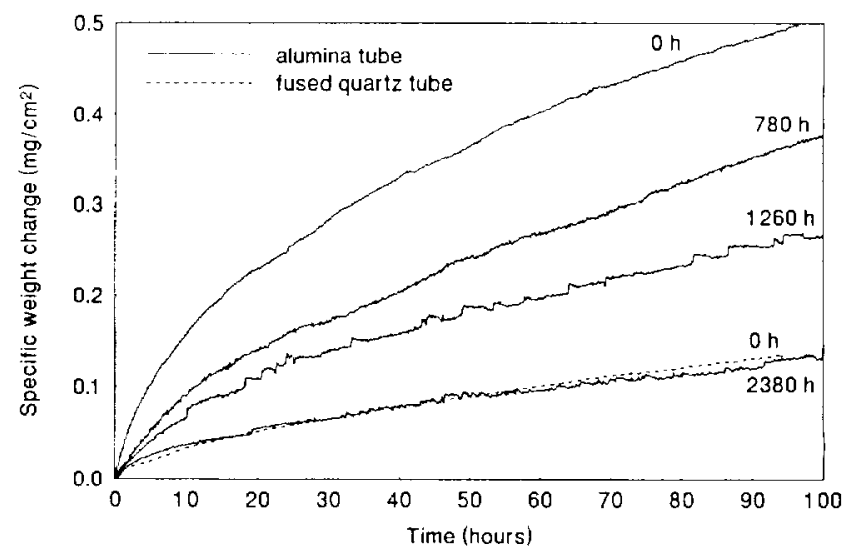

Fig. 6. Effect of $\mathrm{Al} O$ tube age on the oxidation kinetics of $\mathrm{SiC}$ it $1300 \mathrm{C}$ in dry oxygen compared to kinetics obtained in a new fused quart? reaction tuhe. The time noted by each curve is the approximate time the tube hatd been at temperatures between $1200^{\circ}$ and $14000^{\circ} \mathrm{C}$ prior to that given oxidation experiment. 
Acknowledgments: I would like to thank Nathan Jacobson of NASALewis for his contributions to this work. I would also like to thank Don Humphrey of NYMA, Inc., for performing the TGA experiments.

\section{References}

'S. K. Ghandi; Ch. 7 in VLSI Fabrication Principles. Wiley, New York, 1983. 'F. E. Wagstaff and K. J. Richards, "Kinetics of Crystallization of Stoichiometric $\mathrm{SiO}_{2}$ Glass in $\mathrm{H}_{2} \mathrm{O}$ Atmospheres," J. Am. Ceram. Soc., 49 |3] 118-21 (1966).

${ }^{3}$ D. J. Choi, D. B. Fischbach, and W. D. Scott, "Oxidation of ChemicallyVapor-Deposited Silicon Nitride and Single-Crystal Silicon," J. Am. Ceram. Soc. 72 [7] 1118-23 (1989).

${ }^{4}$ L. U. J. T. Ogbuji and E. J. Opila, "A Comparison of the Oxidation Kinetics of $\mathrm{SiC}$ and $\mathrm{Si}_{3} \mathrm{~N}_{1}$, J. Electrochem. Soc., $142[3] 925-30$ (1995).

${ }^{5} \mathrm{E}$. J. Opila, "The Oxidation Kinetics of Chemically Vapor Deposited Silicon Carbide in Wet Oxygen," I. Am. Corum. Sox , $77|3| 730-36$ (1994).
"K. L. Luthra, "Some New Perspectives on Oxidation of Silicon Carbide and Silicon Nitride," J. Am. Ceram. Soc., 74 [5] 1095-103 (1991).

D. S. Fox. "Oxidation Behavior of CVD Silicon Carbide and Silicon Nitride from $1200-1550^{\circ} \mathrm{C}$; unpublished work.

${ }^{\text {R}}$ R. B. Sosman: pp. 97-106 in The Properties of Silica. The Chemical Catalog Co., New York, 1927.

${ }^{4} Z$. Zheng, R. E. Tressler, and K. E. Spear. "The Effect of Sodium Contamination on the Oxidation of Single Crystal Silicon Carbide," Comos. Sci., 33 [4] 545-56 (1992).

${ }^{13}$ E. J. Opila; unpublished work.

'K. L. Luthra, "Theoretical Aspects of the Oxidation of Silica-Forming Ceramics; pp. 23-34 in Corrosion of Advanced Ceramics. Edited by K. G. Nickel. Kluwer Academic Publishers, Dordrecht, Netherlands, 1994.

M. A. Lamkin. F. L. Filey, and R. J. Fordham, "Oxygen Mobility in Silicon Dioxide and Silicale Glasses: A Review," J. Eur. Crram. Soc., 10. 347-67 (1992). 